\title{
Fatal cerebral air embolism complicating esophageal dilation
}

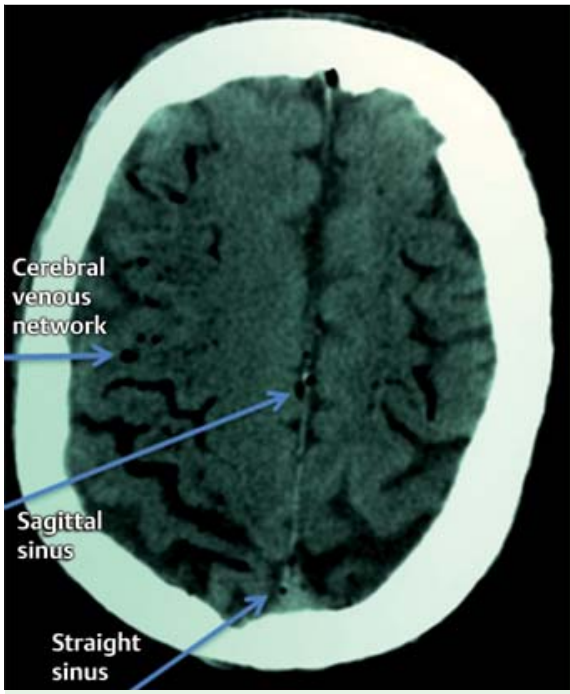

Fig. 1 a, b Computed tomography (CT) scans in a 72-year-old man who underwent endoscopy for an esophageal stricture 6 months after being treated for cardiac adenocarcinoma with a metal stent and radiation therapy for pulmonary me-

We present the case of a 72-year-old man with cardiac adenocarcinoma treated with a metal stent and radiation therapy for pulmonary metastases. After 6 months of this treatment he developed a malignant esophageal stricture. Endoscopy was carried out under moderate sedation and constant monitoring. Dilation with an over-the-scope balloon dilator (CRE single-use, wire-guided esophageal dilation balloon, $240 \mathrm{~cm}$, balloon length $5.5 \mathrm{~cm}$, outer diameter 10-12 mm, Boston Scientific, Natick, Massachusetts, USA) was carried out. The patient's vital signs and oxygen saturation were normal throughout the procedure. However, when flumazenil was administered the patient did not recover. Neurological examination revealed a Glasgow Coma Scale score of 4/15 points, pupils equal and reactive to light, and no focal neurological signs. Cardiac and respiratory functions were stable. Brain computed tomography (CT) revealed bilateral multifocal cerebral air embolism with air bubbles within the sagittal sinus, straight sinus, great vein of Galen, and the cerebral venous network of the cortex ( $\bullet$ Fig. 1), and 24 hours later the patient died.

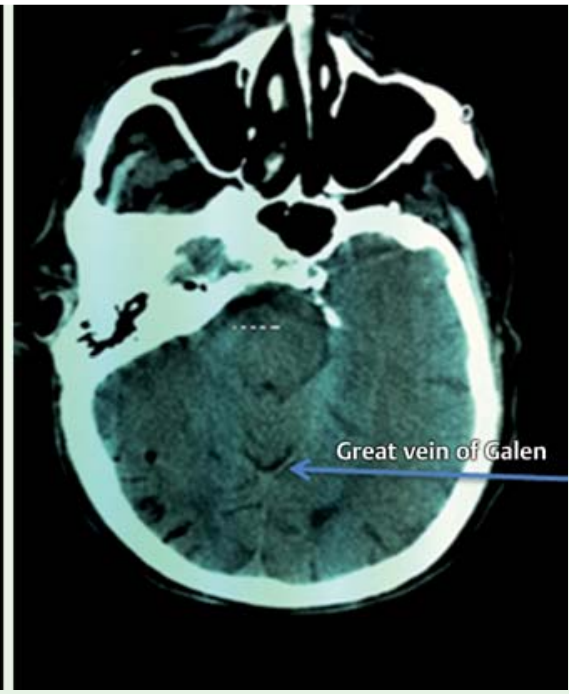

tastases. The scans show bilateral multifocal cerebral air embolism with air bubbles within the sagittal sinus, straight sinus, great vein of Galen, and the cerebral venous network of the cortex.

The entry of air into the vascular system during endoscopy is a serious complication and is usually accompanied by interruption of the mucosal barrier [1-3]. Our patient developed pneumocephalus as a result of gas entry either directly into the arterial system or indirectly through the venous system. Paradoxical embolism via an intracardiac shunt [4] or pulmonary shunts due to metastases cannot be excluded, although hemodynamic instability was not observed. The esophagus is directly in contact with the posterior wall of the left atrium between the mid-posterior part of the atrium and the distal border of the inferior pulmonary veins [5]. Arterial gas entry may have occurred under positive air pressure due to proximity of malignant and radiation trauma. Cerebral air embolism during an endoscopic intervention has not been reported previously, but it should be suspected in case neurological deterioration ensues as the prognosis is poor.

\section{Endoscopy_UCTN_Code_CPL_1AH_2AF}

\section{Competing interests: None}

E. Zampeli ${ }^{1}$, E. Tsagalou ${ }^{2}$, I. Kanakakis ${ }^{2}$, C. Giannopoulos ${ }^{1}$, A. Tzanetaki ${ }^{3}$, K. Vemos ${ }^{1}$, S. Michopoulos ${ }^{1}$

${ }^{1}$ Department of Gastroenterology, Alexandra University Hospital, Athens, Greece

${ }^{2}$ Intensive Care Unit, Alexandra University Hospital, Athens, Greece

${ }^{3}$ Department of Radiology, Alexandra

University Hospital, Athens, Greece

\section{References}

$1 \mathrm{Ha} J$, Allanson E, Chandraratna H. Air embolism in gastroscopy. Int J Surg 2009; 7: 428 430

2 McAree BJ, Gilliland R, Campbell DM et al. Cerebral air embolism complicating esophagogastroduodenoscopy (EGD). Endoscopy 2008; 40 (Suppl. 02): E191 - 192

3 Green BT, Tendler DA. Cerebral air embolism during upper endoscopy: case report and review. Gastrointest Endosc 2005; 61: 620-623

4 Lynch JJ, Schuchard GH, Gross CM et al. Prevalence of right-to-left atrial shunting in a healthy population: detection by Valsalva maneuver contrast echocardiography. Am J Cardiol 1984; 53: 1478-1480

5 Tsao HM, Wu MH, Higa $S$ et al. Anatomic relationship of the esophagus and left atrium: implication for catheter ablation of atrial fibrillation. Chest 2005; 128: $2581-$ 2587

\section{Bibliography}

Dol http://dx.doi.org/

10.1055/s-0033-1344409

Endoscopy 2013; 45: E358

(c) Georg Thieme Verlag KG

Stuttgart · New York

ISSN 0013-726X

\section{Corresponding author}

\section{S. Michopoulos}

Department of Gastroenterology

Alexandra University Hospital

80 Vas Sofias Ave, 11528

Athens

Greece

Fax: +30-213-2162895

michosp@hol.gr 